\title{
Digitization and Manuscripts as Visual Objects: Reflections from a Media Studies Perspective
}

\author{
Liv Ingeborg Lied
}

At the time of writing this essay, libraries and collections worldwide are slowly, but steadily, in the process of digitizing their manuscript collections and making them available online. ${ }^{1}$ The Bibliothèque nationale de France in Paris, the Vatican Library in Rome, and the British Library in London have been in the process of digitizing their manuscript repositories for quite a while. ${ }^{2}$ In recent years, several other holders of large manuscript repositories have announced that they will digitize their collections, in whole or in part; among them the National Library of Greece in Athens. ${ }^{3}$

In addition to the growing digital repositories of major libraries and collections, a series of other online sites have also provided digital images and new tools for exploring manuscripts. Sites, such as E-ktobe, aim to provide digital images and searchable information for all Syriac manuscripts ${ }^{4}$ and the Hill Museum \& Manuscript Library (HMML) has recently launched an online read-

1 The main ideas of this essay were first formulated in the blog post "Digitization and Manuscripts as Visual Objects: Effects of a Media Change" posted on Religion - Manuscripts - Media Culture: (<http://livlied.blogspot.no/2015/o1/digitization-and-manuscripts-as-visual. html $>$ ), accessed on 10/04/19. The revised version of the essay was presented as an oral paper at the "Data Visualization, Digital Paleography and Images-session" of the SBL Digital Humanities in Biblical, Early Jewish, and Christian Studies at the Annual Meeting in Atlanta, Tuesday November 24, 2015. The paper version is available on Academia.edu: (<https://www. academia.edu/24937072/Digitization_and_Manuscripts_as_Visual_Objects_Reflections_ from_Media_Studies_Perspective_SBL_Paper_2015_>), accessed on 10/04/19. Thanks are due to John Durham Peters for his input on a draftversion of the revised essay.

2 See: <https://www.bnf.fr/fr >; <https://www.bl.uk/manuscripts/>; <http://digi.vatlib.it/ news/\#news-0 $>$, accessed on 10/04/19. For an example of a large scale, cross-institutional digitizing project, cf. the Swiss e-codices project. See: <http://www.e-codices.unifr.ch/en>, accessed on 10/04/19.

3 See: <http://www.csntm.org/News/Archive/2015/1/12/CSNTMtoDigitizeManuscriptsat theNationalLibraryofGreece $>$, accessed on 10/04/19.

4 See: $<$ http://syriac.msscatalog.org/>, accessed on 10/04/19. 
ing room for scholars. ${ }^{5}$ Yet other sites may serve as online collaborative workshops where manuscripts are transcribed, translated, or edited, or they may serve as combined archives and connecting tools for scholars working on specific manuscript materials. In effect, although large repositories of manuscripts are still not digitized, these and other recent projects are turning more and more manuscripts into digital objects online. ${ }^{6}$

Images of manuscripts are not only there for scholars who actively seek them in their new online locations. In their capacity as digital objects, manuscripts may be seen as among the winners of the new, hyperconnected academic world, being the perfect combination of old mystery and venerable aesthetics in sharing cultures online. Manuscripts have become academic clickbait, images of manuscripts are favored objects of tweeting and retweeting, ${ }^{7}$ Facebook groups are dedicated to them, ${ }^{8}$ and specialized blogs update their followers regularly. 9

Due to the ongoing digitization of manuscript collections as well as the steady flow of images in social media communication, scholars in the relevant fields are now more regularly exposed to manuscripts and they will become more familiar with the visual aspects of text-carrying manuscripts than ever before. And as time goes by and more libraries will experience the growing demand for digitization of their collections, scholars will probably expect to find manuscripts available online.

Today, scholars are increasingly and to a large degree living digitized lives. The generations of scholars who now make up the faculty at various universities live that life as "digital immigrants" - they did not grow up with it/there. However, the generations that are students at universities now, and those who will become students during the next decades will be "digital natives." ${ }^{10}$ If the

See: <http://www.hmml.org/news--media/sneak-peeks-of-vhmml-reading-room-nowavailable $>$, accessed on 10/04/19.

6 In the present essay, I use the term "digital" to refer to the outcome of transforming an object into a digital code, mediated, and made available, graspable, and socially relevant through a computational device.

7 See: @DamienKempf, 26599 followers the 25th of October 2016. For a critical engagement with this phenomenon see: <http://www.historytoday.com/kate-wiles/monetising-pastmedieval-marginalia-and-social-media $>$, accessed on 10/04/19.

8 When accessed on October 26, 2016, Sexy Codicology, for example, had 10479 followers, and Alin Suciu's Coptic Literature and Manuscripts had 5335 followers.

Roberta Mazza's blog Faces and Voices (<https://facesandvoices.wordpress.com/>), Adam McCollum's British Library Medieval Manuscripts Blog. See: <http://blogs.bl.uk/digitisedmanuscripts/ index.html $>$, accessed on 10/04/19, just to mention a few.

10 Expression coined by Marc Prensky, "Digital Natives, Digital Immigrants", On the Horizon 9:5, 2001, 1-6. 
process continues as it does now, looking up a manuscript online will be the intuitive thing to do for these generations of new scholars and they will do it with the skill and literacy of a native. ${ }^{11}$

In this essay, I wish to present and reflect on some possible effects of the ongoing digitization on scholarly engagement with manuscripts and the texts contained in them. I wish to approach this process in terms of a media shift, and I will be drawing on insights from the field of media studies - media history/media archaeology, and studies of digital and visual media in particular - in order to hypothesize about its possible effect on scholarly practices. I will explore the digitization of manuscripts as a case study, discussing how digitization may change scholarly practices in fields that apply manuscripts and their texts as their primary sources. As such, this essay can be approached as part of, or at least inspired by, the so-called Third Wave Digital Humanities Studies, perceived as studies exploring the effect of the digital turn on the practices, epistemologies and paradigms of Humanities scholarship. ${ }^{12}$

This current media shift could fruitfully also be contextualized in perspective of the long durée of media history, seeing the turn to digital images as yet another remediation of materially extant texts in manuscripts. Manuscripts are themselves old media. Their folia mediate both the text inscribed in the writing area of the pages and the verbal, as well as non-verbal, notes inscribed in the margins and elsewhere. Furthermore, manuscripts and their texts have been remediated throughout history in the form of, for instance, subsequent manuscript copies, as well as through printed critical editions, facsimiles, microfilms, and analogue photos. In this sense, the most recent digital turn is but one in a series of "turns" that have remediated the texts found in manuscripts.

It should be noted that the current essay is explorative and forward-gazing in nature. This essay asks questions and presents hypotheses: it does not provide fixed conclusions based on empirical research. The questions that are posed in the following are:

11 At the time being, one of the challenges to a fruitful engagement with digital manuscripts is that it is difficult to get an overview of the available resources. See: $<\mathrm{http} / / / \mathrm{www}$.dot porterdigital.org/>, accessed on 10/04/19, HT Caroline T. Schroeder on Facebook. Recently, portals offering ordering tools and lists of digitized collections are starting to appear, e.g., the overview of digitized manuscripts in Syriac, Arabic and Garshuni at Syria.ac. See: $<$ http://syri.ac/digimss >, accessed on 10/04/19.

12 Berry, David M., "The Computational Turn: Thinking about the Digital Humanities", Culture Machine 12, 2011, 1-22, particularly p. 4 and 9. 
How may the increased presence of manuscripts online contribute to a change in editing practices, as well as the academic reader's expectations to the content and format of critical editions? How may the increased presence of digitized manuscripts online affect studies of manuscripts beyond editorial practices? (How) will the digitization of manuscripts change the needs of scholars to access manuscripts in libraries and collections?

\section{2 \\ Media Change, Digital Turn, Visual Media}

During the last 50 years, media scholars have given much attention to media changes and their effects, from the introduction of writing in largely oral societies in Antiquity to the contemporary digital and connective turn. These turns and their effects have been theorized differently across the broad field of media studies, and beyond. ${ }^{13}$ The ways in which the relationship between humans and technology is construed differ, including: the degrees to which technology is ascribed agency; and, the extent to which a human person is regarded a discrete entity or better understood as networked, distributed, extended, or something the world flows through. Likewise, the interconnectedness of various media and the ways in which the relationship between media and cultural change (and vice-versa) are viewed are among the aspects that vary. The following sketch is an eclectic and heuristic presentation of some points of particular relevance to the discussion of the present essay.

A first, often stressed, feature that serves as a fundamental point of departure in the field of media history/media archaeology is the shared basic contention that media matter, and that changes in technological media will influence human sensation, experience, knowledge, and/or practice. ${ }^{14}$ This widespread and foundational claim has typically been formulated as a response to other academic perspectives on history that are deemed blind to the role of media, or accused of seeing media only as tools. Instead, in these fields media technology has been approached, for instance, as embedded in human experience, or gradually creating new human environments, opening up for extended sense perception, and thus changing the way in which we think and

13 The assumption of a digital turn has of course also been criticised. See, for instance, Mitchell, W.J.T., Image Science: Iconology, Visual Culture, and Media Aesthetics, Chicago and London: The University of Chicago Press, 2015, 115 .

14 It almost goes without saying that academic cultures and practices should be regarded just as any other human practice. Academic practices are not beyond or above these shifts, coolly looking down on them: they are integral parts of them. 
act. Thus, in some oft cited, emblematically used references, it is hypothesized that media technology will create epistemic changes. It will change the perception, memory, communication, and social practices surrounding the mediated object, and as such it is held that we cannot understand human history without also exploring the materialities of communication; that is, the media of historical and cultural transmission. ${ }^{15}$

A second point, drawn from discussions in the fields of media aesthetics, visual media and visualization studies is the current increasing importance of the computer medium, the screen interface, and the mode of the image. ${ }^{16}$ With the growing privileging of computational devices as society's main medium of communication, it has been held that information will increasingly be visually formatted and displayed, and subsequently digested through the sense of sight. Such a development would bring the image into the center of communication and add weight to the role of visual perception as a cognitive activity, also in academic pursuits. ${ }^{17}$

For sure, the claim as to the increasing dominance of the visual and the mode of the image is contested..$^{18}$ Current debates on digital images and digital materiality discuss the aspects of referentiality and of realism, which point to more complex views on the role of the visual. ${ }^{19}$ On the one hand, these debates respond to assumptions that the digital images of objects are less real than the objects themselves, or "unreal" altogether. On the other hand, they respond to the notion that an image is a one-to-one representation, a stand-in or simulation based on the idea of an indexical relation between image and the object represented in the image. ${ }^{20}$ It is of particular importance to the current essay that these debates have pointed out how a digital image is, in crucial ways,

15 Emblematically and representing the variety of perspectives involved: Kittler, Friedrich, Nedskrivningssystem 1800-1900, Göteborg; Glänta production, 2012, esp. 379. Originally in German: Aufschreibesysteme1800·19oo, München: Fink, 1985. McLuhan, Marshall, Understanding Media: The Extensions of Man, New York: McGraw Hill, 1964, 5-6, 21. Lyotard, Jean-F., La condition postmoderne, Paris: Les éditions de minuit, 1979. Altheide, David, Snow, Robert, Media Logic, Beverly Hills, CA: Sage, 1979. Latour, Bruno, "Visualization and Cognition: Thinking with Eyes and Hands", Knowledge and Society 6, 1986, 1-40. Kress, Gunther, Literacy in the New Media Age, Literacies; London and New York: Routledge, 2003, 1-7.

16 In particular, Rudolf Arnheim, Visual Thinking, London: Faber and Faber, 1970. Mitchell, W.J.T., Image Science, and confer the main ideas and foci of Kittler, Friedrich, Nedskrivningssystem (Aufschreibesysteme) 1800- 1900.

18 Mitchell, W.J.T., Image Science, esp. 115, 125, 130.

19 Ibid., 49-64.

20 Ibid., 53 and Bolter, David, Grusin, Richard, Remediation: Understanding New Media, Cambridge, MA: MIT Press, 2000. 
"another thing" that deserves to be studied and understood in its own right and in its own context. Although related and intermingled with the object it portrays, a digital image is not a mere representation of the physical object appearing in the image, and hence not reducible to that object. Being a digital image, the image is part of a new constellation and dependent on a new interface. Digital images become part of and are dependent on the digital space in which they appear. They share in a specific configuration that instantiates the information that is there for us to study.

The implications of this theoretical nuancing of the ontology and epistemology of the visual mode are important to the current discussion of digital images of text-carrying manuscripts, because they highlight the multimedial access to the texts in manuscripts and the multisensory approach necessary for studying them. On the one hand, the digitization of manuscripts makes them visually available as digital objects and thus produces different and complementary possibilities of study. On the other hand, even though the increasing availability of digital images privileges the sense of seeing and the visual aspects of manuscripts and their texts, this does not mean that the media that are represented in such images (the manuscripts) will be superfluous, that other aspects of these media are rendered uninteresting, or that other modes of interaction will be considered dated. Rather, the image in its digital space and the palpable, material manuscript in its given physical location are different constellations and different mediations of a text. As such, the visually available digital object is an addition to the media and modes of interaction that we already have. It invites different forms of sensation and usage, it is part of different practices, and it tends to produce different sets of stories connected to it. $^{21}$ If we want to explore the potential effects of the scholarly use of digital manuscripts, then we need to study how this new mediation may create new perceptions and practices and how it may be related to, differ from, and/or intertwined with interactions with other, "old," modes of mediation.

\section{$3 \quad$ Digitized Manuscripts, Editorial Practices, Readers' Expectations}

In the light of these theoretical musings, it is time to pose the first question: how may the increased presence of visually available manuscripts online contribute to a change in editing practices, as well as the academic reader's expectations to the content and format of critical editions? 
To suggest some possible answers to this question, I will start by reiterating how scholars of biblical studies, as well as scholars of other fields specializing in the editing and interpretation of ancient texts, have typically become acquainted with manuscripts during the last centuries. I will also discuss how that in turn may have affected the imaginations and expectations of these scholars.

Until recently, manuscripts have been physical artifacts that are kept, for instance, in monastery storage rooms, on library shelves, or in private collections - and, of course, they still are, since "old media rarely die."22 Although many manuscripts are certainly lost, papyrus, parchment and paper have proven to be relatively durable materials that are apt for communicating texts to posterity. However, for various reasons, these physical artifacts have typically been seen and engaged only by a select few. ${ }^{23}$ Some collections have restrictive access policies. Some scholars are never able to visit special collections due to economic, communicational, or technological limitations. Importantly, in many fields, such as New Testament Studies, a traditional division of labor between those who edit texts and those who interpret them has shaped a contention that only the editors have a real need to study manuscripts. ${ }^{24}$

In addition to being tangible artifacts in their physical locations, manuscripts have been remediated via microfilms, analogue photos and facsimile editions. However, for a long time the main medium of acquaintance with manuscripts has been print editions of the texts contained in the manuscripts. Hence, its major presence in the everyday life of most academics has been this remediated form where the manuscript is represented symbolically as a siglum in the apparatus. It is likely that this remediation has affected the way that manuscripts have been imagined. As Brent Nongbri has pointed out, the manuscript, qua siglum, has been part of a symbolic academic language that scholars of ancient texts have had to learn - in addition to Greek, Hebrew and other ancient languages. ${ }^{25}$ In this context of use and mediation, the manuscript has been of interest primarily due to the text found in the writing area. It has been

22 Peters, John Durham, The Marvelous Clouds: Towards a Philosophy of Elemental Media, Chicago and London: University of Chicago Press, 2015, 23.

23 "[The archive] used to be the abode of secrets, silence, of dust", Røssaak, Eivind, Archive in Motion, 16.

24 Hurtado, Larry, The Earliest Christian Artefacts: Manuscripts and Christian Origins, Grand Rapids, MI: Eerdmans, 2006, esp. the introductory pages. In other fields, such as the study of the Dead Sea Scrolls, scholars have so far been working on manuscript materials to a much larger degree.

25 Nongbri, Brent, "A Very Brief Introduction to the Critical Apparatus to the Nestle-Aaland", revised 2006, 3. Available online at: <https://www.marquette.edu/maqom/Apparatus Guide.pdf>, accessed on 10/04/19. 
discoursed in the vocabulary of a text critical paradigm in terms of a "text witnesses," first and foremost pointing away from itself and its own materiality and cultural context towards an ancient text.

However, when manuscripts are increasingly available as digital objects, they have now become visually accessible in all their unruly glory. They are only "a click away," and as suggested initially, when more libraries digitize their collections, the manuscripts will subsequently be expected to be no more than a click away. Hence, during the next decade(s) manuscripts may be visually available to the groups of scholars who already have the necessary language competences and who know the contents of the texts from editions very well through their exegetical work on texts, but who have traditionally not engaged much with manuscripts.

How will this situation change editing? Scholars who have worked on texts based both on studies of the manuscripts and the use of print editions know how different the visual impression of a manuscript page and a page of a critical edition may be. Scholars acquainted with manuscripts also know how poorly the critical apparatus may sometimes represent the various features on the manuscript page. The hand may, for instance, be difficult to read, words and letters may be open to interpretation, texts may be lacunose, the script may be continuous, or there may be no paragraph- or other division markers on the page. Manuscript pages may be messy too. They typically contain notes, glosses, corrections and erasures. They may also contain other paratextual features, study and memory aids, designed to communicate between text and reader.

In traditional print editions, some of these traits have been treated in the apparatus or in footnotes and commentary. Others have been overlooked, regarded as irrelevant, or as clutter. It might also have been regarded difficult or too expensive to reproduce paratextual features such as these in a printed book. However, now, when the manuscripts are available online, the unruly elements of a manuscript page are there for everyone to see. These elements may even come as a surprise to those who did not know of their existence.

This media change may constitute a challenge to dominant editorial practices per se because it will affect scholars' imagination of and acquaintance with, manuscripts. When academic users of print editions know that the manuscripts are there for them to consult online, will the representation of the messy variability present on manuscript pages in the form of a critical apparatus be satisfactory to them? And when editors and their publishers know that readers will be able to consult pictures of the manuscripts, will they change the way that they represent the manuscripts and the various elements found on 
manuscript pages, knowing that the elements of the manuscript page are visually available for their readers?

A look at some examples of ongoing projects online may suggest both how current editorial practices are already changing due to and alongside new media technology, and display how digitized manuscripts and the scholarly discourse about them are explicitly part of and formed by new media constellations. Digital manuscripts do not circulate in a void: they are often part of a larger online media package - sometimes in ways that are not traditionally associated with academic genres.

A look at the so-called Homer Multitext Project shows some of the opportunities of a current digital edition. ${ }^{26}$ In this critical edition of Homer, the editors bring in marginalia and annotations in addition to the text in the writing area by digitally annotating the manuscripts. In this way, they use the possibilities provided by technology to make the interplay of these text units, which share the page in the manuscript, visible also in the edition. As a result, the text of the writing area is not privileged in the same way as it was previously.

Other examples can be seen in the online sites Ancient Lives and the New Testament Virtual Manuscript Room. ${ }^{27}$ These sites show, among other things, how constellations and genres known to users from other media contexts have been brought in and are allowed to shape the engagement with the manuscripts. These sites typically include a blog or chat function, or they may include a Wiki. They connect their users "social media style" and the users apply social media language genres in their communication. The sites make engagement with manuscripts take place online and as a collaborative effort, and they are in this sense archive and communication in tandem - which from a theoretical and historical perspective is an interesting combination. ${ }^{28}$ Hence, digital manuscripts are part of complex online media packages. It is likely that the entire package, not only individual digital images, may shape the way that we imagine manuscripts, how we conceptualize editorial practices and our involvement in them, and what we expect from a critical edition.

26 See: <http://www.homermultitext.org/>, accessed on 10/04/19. See also, Clivaz, Claire, "Homer and the New Testament as "Multitexts" in the Digital Age", Scholarly and Research Communication 3/3, 2012, 1-15. Schroeder, Caroline T., "The Digital Humanities as Cultural Capital: Implications for Biblical and Religious Studies", Journal of Religion, Media and Digital Culture 5/1, 2016, 21-49.

27 See: <https://www.ancientlives.org/> and <http://ntvmr.uni-muenster.de/>, both accessed on 10/04/19. Thanks are due to Alin Suciu for pointing me to these sites.

28 See: Røssaak, Eivind, Archive in Motion, 12, 19. Further, Kress, Gunther, Literacy in the New Media Age, 5, 9 10. Berry, David M., "Computational Turn", 8. 
It is time now to address the second question: how is it likely that the increased presence of digitized manuscripts online may affect studies of these manuscripts, beyond its effects on editorial practices?

A still hypothetical answer may be that when manuscripts become visual objects online they will appeal to other categories of scholars and lend themselves to other kinds of studies than the ones we have commonly seen so far. As pointed out above, many subfields under the larger umbrella of biblical studies have been characterized by a division of labor between editors and exegetes, which has produced a division between scholars who are trained in working on manuscripts and scholars who are not. With the increased visual availability, scholars who have been exegetes may bring new interpretative tools to the study of manuscripts and their various texts, beyond those their colleagues have traditionally taken interest in, and hence giving rise to new approaches. During the last few decades, we have seen a general surge of interest in the materiality of artifacts, in the role of the medium, as well as in aesthetics, scribalism and scribal cultures, paratexts and marginalia, and reader practices in these fields. Digitized manuscripts have become an available source material for scholars who are influenced by these recent research debates.

If this proves correct, we may expect to see more studies of the various relationships between text and manuscript, and between text, manuscript and their active readers. There will probably be more studies of the role and importance of manuscript layout and aesthetic elements, as well as scribbles, doodles, notes and other text units sharing the manuscript pages. Studies of these elements in manuscripts are certainly not a novelty in the Academe, ${ }^{29}$ but digitization and online availability will probably feed this rush, which will also be felt in biblical studies, since there is still much more to discover. We may, for instance, see more studies of manuscript pages as discursive and dialogical spaces, as spaces where the text in the writing area is sometimes contested and negotiated by later readers. ${ }^{30}$ We may also see more studies of manuscripts

29 See, for instance, and emblematically, Carruthers, Mary, The Book of Memory: A Study of Memory in Medieval Culture, Cambridge Studies in Medieval Literature 7o, Cambridge: Cambridge University Press, 1990. Derrida, Jacques, “This is Not an Oral Footnote”, in: Annotation and Its Texts, ed. Stephen A. Barney, New York: Oxford University Press, 1991, 192205. Camille, Michael, Image on the Edge: The Margins of Medieval Art, London: Reaktion Books, 1992.

30 Penn, Michael Philip, "Monks, Manuscripts, and Muslims: Syriac Textual Changes in Reaction to the Rise of Islam", Hugoye: Journal of Syriac Studies 12:2, 2009, 235-257; Penn, Michael Philip, "Moving Beyond the Palimpsest: Erasure in Syriac Manuscripts", Journal of Early Christian Studies 18:2, 2010, 261-303. 
that were transformed and given new and different functions by later readers than the functions envisioned by the producers of the artifact. ${ }^{31}$

A prominent example of such a project is the ongoing, Munich-based Paratexts of the Bible-project, headed by Martin Wallraff and Patrick Andrist. This project explores Greek biblical manuscripts, aided by new digital imaging, focusing on the roles of individual manuscripts as textual objects that were read and interpreted, tracing paratextual elements and their mediating functions. ${ }^{32}$ Such studies of manuscripts as culturally situated artifacts will probably both add to and challenge studies that primarily take interest in the text of the writing area and the manuscript's function as text witness or text carrier.

The increasing visual availability of manuscripts is also likely to give rise to some new challenges. There is no such thing as an easy, carefree media shift. What was once a question of availability may now increasingly become a question of media literacy - both in terms of being able to maneuver digital sites and being trained in reading manuscripts. Even though the manuscripts are in principle available, scholars must be able to retrieve the relevant materials, master the technology and understand what they see on manuscript pages. Reading Late Antique and Medieval manuscripts requires proper training. Consequently, the need for interdisciplinary cooperation will be evident and new types of literacy will be in demand. ${ }^{33}$

\subsection{Palpable Media, Visual Media, Mixed Media}

The third and last question that I posed above was: (how) will the digitization of manuscripts change the needs of scholars to access the manuscripts in libraries and collections?

One of the motivations behind ongoing digitization of caches of manuscripts is the preservation of vulnerable artifacts. The assumption is that when manuscripts are digitized and available online, the need for consulting the physical artifact will decrease. Due to assumptions like this, the digitization of manuscripts has already led to - and will probably continue to lead to changes in access policies in libraries and collections. The wish to protect the

$31 \quad$ Childers, Jeff, "You Will Find What You Seek': the Form and Function of a Sixth-Century Divinatory Bible in Syriac", in: Snapshots of Evolving Traditions:Jewish and Christian Manuscript Culture, Textual Fluidity, and Material Philology, eds., Lied, Liv Ingeborg, Lundhaug, Hugo, Texte und Untersuchungen zur Geschichte der altchristlichen Literatur 175, Berlin: De Gruyter, 2017, 242-271.

32 See: $<$ http://paratexbib.eu/index.html $>$, accessed April 21, 2017.

33 Further, Lied, Liv Ingeborg, "Bible as Notepad: Exploring Annotations and Annotation Practices in Biblical Manuscripts", in: Bible as Notepad, ed., Lied, Liv Ingeborg, Maniaci, Marilena, Manuscripta Biblica 3, Berlin: De Gruyter, 2018. 
manuscripts is noble and sometimes an absolute necessity. Furthermore, accessible digital images of a manuscript are clearly much better than having no access to the manuscript in question at all. Yet, it would be a fundamental misunderstanding of the role of media, and the intermingled processes of scholarly sensation, perception and practice, to assume that the availability of online digital images will do away with the need to consult the palpable, material manuscript.

In terms of practical research, at least three types of challenges are likely to occur. First, images, also high-resolution digital images, may hide or misrepresent features of the manuscript. Folds in the parchment may for instance hide letters that remain inaccessible in an image. Likewise, fly droppings and ink are frequently hard to tell apart in digital images. The ability to discern between the two may matter both to interpretation of words in pointed scripts as well as to delimitation criticism. Second, depending on the aim and profile of the research project, some studies will still be dependent on an exploration of the physical artifact. There is more to the manuscript than its visual features. Its texture, weight, and smell may for instance matter to studies of manuscripts as ritual objects. These features do not reach us through the computer screen. Third, it is crucial to keep in mind that images are far from neutral representations of the manuscript page. The remediation of manuscripts in digital images is also paradigm driven. The focus and framing in images may for instance be driven by, and mirror, the practices and needs of textual critics. Some digitization projects have produced high quality images of the text in the writing area, but have kept text units in the margins of the pages, fully or in part, outside the picture frame. Texts inscribed in the first and last folios and flyleaves of a codex are sometimes not included at all.

In theoretical terms, these insights can be rephrased like this: just as the traditional print edition and its apparatus is but a limited representation of the text and the manuscripts that contain it, a digital image of a manuscript is another limited representation of the text contained in physical, tactile (and smelly) artifacts. There is no doubt that digital imaging provides new opportunities and that high quality images are invaluable tools for scholars, ${ }^{34}$ but imaging still remains a particular type of mediation, which may be apt for some types of scholarly practices and some research questions but not for all. The

34 This essay does not deal with advanced imaging, which promises to provide opportunities of research beyond the features that are described here. Advanced imaging may for instance bring out the texture of the writing surface in ways not otherwise accessible through sight and touch. In this way, images may provide opportunities that the physical object cannot. I am thankful to Todd Hanneken, as well as to one of the anonymous reviewers, for this observation. 
images are not identical with the manuscripts, and the visual mode does not grasp or account for all of the qualities of a manuscript: digital images should be seen as a "deepening of the referent, not its disappearance." ${ }^{35}$ We need to acknowledge the need for a multimedial approach to manuscripts. We should also recognize the limitations and opportunities of different media technologies. Those who work on manuscripts will frequently need to approach them across interfaces and formats - both as physical artifacts, as sigla in critical editions, and as visually available digital objects. One is not necessarily reducible to the other in scholarly practices.

This essay has barely scratched the surface of a complex, ongoing, transformation of academic practices that has been ushered in by the digital turn. In this essay, I have aimed to point out how ongoing digitization projects and their resulting creation of digital repositories of manuscripts have the potential to change the ways in which scholars of manuscripts and their texts may engage with their source materials. Manuscripts, which to many have primarily been approached as "witnesses" to an older text and which have been available symbolically as sigla are now increasingly present as visually available artifacts. The media packages that frame the engagement with manuscripts are also changing. New technology and new interfaces enable editors to represent the text units present on manuscript pages in new ways, and academic practices of translation, transcription and commentary are becoming enmeshed with widespread social media practices.

There is potential to further explore how digitization may influence the perceptions of the physical artifacts manuscripts arguably are, including how media have historically shaped the way that we study texts and will probably do it again, how editorial paradigms and media technology have been and are intertwined, as well as how new mediations of manuscripts may provide new areas of research.

Importantly, future explorations of such aspects of scholarship may also open up for further deliberations on scholarly epistemologies and practices. For one, it is likely that the digital turn may affect the notion of the competent professional. For instance, the imagination of the biblical scholar in the new generation of "digital natives" will probably include other components than the image of the ideal biblical scholar of the past. Engaging the biblical text for 
scholarly purposes will increasingly demand a high degree of digital literacy and the longstanding division of labor between editors and exegetes will probably be challenged and crisscrossed as well. Such reevaluations of key professional expectations may subsequently, or simultaneously, involve a potential change of the discipline itself.

Another interesting aspect that clearly demands more attention in future study is the ways in which the digital turn may influence scholars' notions of the very books and texts that constitute much of their main focus. If, and when, print editions of texts are no longer the dominant medium through which scholars get acquainted and engage with books and texts, we open the floor for the unruly realities of the manuscript page. It remains to be seen how the visual availability of the manuscript page, in all its messy glory, may influence the textual imagination of the next generation.

\section{References}

Altheide, David, Snow, Robert, Media Logic, Beverly Hills, CA: Sage, 1979.

Arnheim, Rudolf, Visual Thinking, London: Faber and Faber, 1970.

Berry, David M, "The Computational Turn: Thinking about the Digital Humanities", Culture Machine 12, 2011, 1-22.

Bolter, David, Grusin, Richard, Remediation: Understanding New Media, Cambridge, MA: MIT Press, 2000.

Camille, Michael, Image on the Edge: The Margins of Medieval Art, London: Reaktion Books, 1992.

Carruthers, Mary, The Book of Memory: A Study of Memory in Medieval Culture, Cambridge Studies in Medieval Literature 70, Cambridge: Cambridge University Press, 1990.

Clivaz, Claire, "Homer and the New Testament as 'Multitexts' in the Digital Age", Scholarly and Research Communication 3/3, 2012, 1-15.

Derrida, Jacques, "This is Not an Oral Footnote", in: Annotation and Its Texts, ed., Stephen A. Barney, New York: Oxford University Press, 1991, 192-205.

Hurtado, Larry, The Earliest Christian Artefacts: Manuscripts and Christian Origins, Grand Rapids, MI: Eerdmans, 2006.

Kittler, Friedrich, Aufschreibesysteme 180o-19oo, München: Fink, 1985.

Kittler, Friedrich, Friedrich, Nedskrivningssystem 1800-1900, Göteborg; Glänta production, 2012.

Kress, Gunther, Literacy in the New Media Age, Literacies, London and New York: Routledge, 2003. 
Latour, Bruno, "Visualization and Cognition:Thinking with Eyes and Hands", Knowledge and Society 6, 1986, 1-40.

Lied, Liv Ingeborg, "Bible as Notepad: Exploring Annotations and Annotation Practices in Biblical Manuscripts”, in: Bible as Notepad, ed., Liv Ingeborg Lied, Maniaci, Marilena, Manuscripta Biblica 3, Berlin: De Gruyter, 2018.

Lyotard, Jean-F., La condition postmoderne, Paris : Les éditions de minuit, 1979.

McLuhan, Marshall, Understanding Media: The Extensions of Man, New York: McGraw Hill, 1964.

Mitchell, W.J.T., Image Science: Iconology, Visual Culture, and Media Aesthetics, Chicago and London: The University of Chicago Press, 2015.

Nongbri, Brent, "A Very Brief Introduction to the Critical Apparatus to the NestleAland", revised 2006, <http://www.marquette.edu/maqom/ApparatusGuide.pdf >.

Penn, Michael Philip, "Monks, Manuscripts, and Muslims: Syriac Textual Changes in Reaction to the Rise of Islam", Hugoye:Journal of Syriac Studies 12:2, 2009, 235-257.

Penn, Michael Philip, Michael Philip, "Moving Beyond the Palimpsest: Erasure in Syriac Manuscripts”, Journal of Early Christian Studies 18:2, 2010, 261-303.

Peters, John Durham, The Marvelous Clouds: Towards a Philosophy of Elemental Media, Chicago and London: University of Chicago Press, 2015.

Prensky, Marc, "Digital Natives, Digital Immigrants", On the Horizon 9:5, 2001, 1-6.

Røssaak, Eivind, “Archive in Motion: An Introduction", in: The Archive in Motion: New Conceptions of the Archive in Contemporary Thought and New Media Practices, ed., Eivind Røssaak, Oslo: Novus Press, 2010, 11-26.

Schroeder, Caroline T., "The Digital Humanities as Cultural Capital: Implications for Biblical and Religious Studies", Journal of Religion, Media and Digital Culture 5/1, 2016, 21-49. 